\title{
On Microsociology of Toys: Material Turn and Non-Symbolic Interactionism
}

\author{
Victor Vakhshtayn
}

\begin{abstract}
Everyday face-to-face interaction is the domain of unquenchable interest for microsociologists. However recent changes in sociological theory (e.g. "material turn", actor-network theory development) led to some reconceptualisations of the very notion of interaction. The concept of face-to-face relationship is broadened and includes now communication with toys and other "existential objects". What role such animated objects play in assembling and reassembling social interaction? What is emotional dimension of human-toy-communication? And what theoretical language should we chose to talk about toys in non-trivial sociological way? In this brief article I will try to answer these questions.
\end{abstract}

Index Terms-Toys, frame analysis, microsociology, transposition, affordance, inscription, emotional investment.

\section{INTRODUCTION}

Toy as a simple material object is a phenomenon familiar to all of us (or at least to the generation of pre-computer games era). Erving Goffman lecturing at the University of Manchester in the late 1960-s mentioned interaction of children with playthings as the best model for understanding human interaction per se. Child-toy communication provides us with the great examples of "framing", "reframing", "keying", "fabrication", "anchoring" and "layering" - all the hidden interactional mechanisms Goffmanian analysis is obsessed with. Though today sociological theory still remains silent about two peculiar questions:

1) How the material playthings are incorporated in the very texture of the Social?

2) What is their impact on it?

In other words how the social world is constituted, framed and re-produced by human-toy interaction? In this paper I shall try to answer these questions from microsociological standpoint using two key theoretical resources: frame analysis and sociology of materiality.

\section{Symbol vs. ToOL}

Conceptualizing toys sociologists usually involve - either implicitly or explicitly - two root metaphors borrowed from allied sciences. One is the "toy as a symbol". Toys are seen as signs, writings that Culture, Class or Society imposes on the world of children. (That conceptualization is used predominantly in history and cultural studies.) Another conceptual metaphor is the "toy as a tool" - mostly a tool for

Manuscript received October 11, 2013; revised November 28, 2013.

Victor Vakhshtayn is with the Russian Presidential Academy of National Economy and Public Administration (e-mail: sociology@universitas.ru). socialization processes. Central question in this perspective: what kind of behavioral / psychological patterns are formed by playing with this particular doll or toy rifle? (That question formulated by N. Krupskaya in her paper on Soviet pedagogy was taken ultimately seriously by Russian school of cultural psychology).

Two conceptual metaphors are commonly opposed to each other. G. Brougere in his short paper 'The toy and the sociology of childhood" argues that "...the toy is more commonly studied in relation to the child's psychology... The result is that the toy tends to be studied as a child's tool, an instrument in its development, incorporated in the individual dynamics which enable the child to emerge from childhood! Our purpose here is, in a sense, quite the opposite: we wish to apprehend how the toy leads the child to be a child, to affirm itself socially and culturally as such, to see how it contributes to producing the childhood of our societies." [1]. Brougere's semiological approach offers another conceptualization: "What in fact determines a toy above all else is what it represents (a human being, an everyday object such as a telephone). It is of course a representation, an image, that is to say a 'second-degree' object." That theoretical move allows application of wide range of semiotic instruments to the world of material toys, e.g. Ogden-Richard's triangle that distinguishes reference and referent of any toy-symbol. Or Brourger's own triangle that connects representation with beneficiary and function.

Cultural analysis underlines meanings and values attributed to a material objects by children, their parents, and the larger society. In addition to anti-psychological rhetoric it frequently implies some sort of cultural criticism: "Guns and other 'war toys' are linked to violence and aggression in children [2]-[6], Dolls and 'domestic role play' toys receive criticism for their perpetuation of traditional gender role behavior [9]-[12]. Video games and toys tied in with television programming are criticized for their negative effects on children's imaginations and for the crassly commercialized nature of the play they promote..." [13]. As we see in its understanding of a long-term effects cultural analysis is not so different from traditional psychological approach.

What unites psychological and cultural perspectives is the neglecting of a toy as a material object enacted in interaction here-and-now. Toy's concreteness and materiality escape researchers' attention as soon as "values", "meanings" or "long-term psychological effects" and "functions" are pushed into the foreground. Constructing their models of explanation both psychologists and cultural students are tending to focus on macro- over micro-, using Culture, Society or Psychic as a hidden source of causality or as an 
omnipresent substance of change.

Choosing between Psychic and Culture, between Tool and Symbol is choosing of two evils. And as it often happens with evils they perfectly supplement each other. To sketch the possible alternative framework for toys study let me provide you with the brief illustration.

\section{THE BABY CARRIAGE AND INTERACTIONIST ALTERNATIVE}

In 1998 I worked in Israeli kibbutz. Originally it was true socialist kibbutz established by the labor movement, and according to its values and principles all property - including toys - belonged to the community. However by the end of XX century situation changed dramatically (as almost everywhere in kibbutzim). Next day we arrived I found the baby carriage, constructed in the form of a toy car, equipped with steering wheel and pedals. So the role of engine was delegated to a parent, while kid could drive choosing the direction freely.

The friends of mine and I were amazed by that device! Immediately we understood the baby carriage as a materialization of the democratic spirit, the freedom of choice and the very essence of social democracy. Kibbutz values were creatively and resourcefully implemented in that construction. At the same time we sow it as the best tool for the upbringing of responsible and self-confident community member, as the crucial part of the famous kibbutz experiment in socialization.

Later on we realized that the steering wheel was not connected to the wheels.

Immediately friends of mine suggested another interpretation. The baby carriage was presented as the best example of kibbutzim ideological crisis. Community's everyday life and its original values were seen disconnected from each other just as the wheels from the steering column. Psychologically speaking the baby carriage was definitely the worst example of Batesonian double-bind communication. From the early childhood a kid getting used to adults' double standards, acquiring an external locus of control.

As we can see now in these two opposite narratives "psychological" and "cultural" arguments are not opposed to each other, on the contrary they are mutually complementary. Two arguments work together linking the concrete material immediately present object to its hidden cultural origins and psychological outcomes. More precisely, they link Culture to Psychic directly by removing concrete material phenomenon from the equation.

What is the possible theoretical alternative? What if we try to understand the baby carriage not as an implementation of immaterial forces but as here-and-now present material object? What particular features of a human-toy-interaction will be considered as relevant then?

Moving to the micro-level of theoretical scale can provide a new ground for the conceptualization. That move was firstly suggested by symbolic interactionists. Donald Ball in his intriguing paper 'Toward a Sociology of Toys: Inanimate Objects, Socialization, and the Demography of the Doll World' offered the definition: "Toys... are a part of the interactional settings, the socially defined - and defining situations of children" [5]. As Ball puts it “...[This] perspective, proceeds from the assumption that although toys are inanimate, passive objects, it does not follow that they are without effect upon those who come in contact with them. Just as the presence or absence of books in the home may be one of the factors encouraging or discouraging the child to read, so too may toys be one of the environmental determinants of the child's lines of socially relevant action." The problem that the interactionist approach couldn't solve is the dualism of symbolic and material. That's why Ball has to introduce a new continuum, some kind of a scale from material to symbolic: "Thus, although at one level toys may be 'mere things' or objects, at another they may be invested with social meanings which have their own consequences for socialization, especially as regards roles, identity, situational definition, or more generally, the social construction of reality itself" [5].

Thereby the baby carriage I'm particularly interested in is a "mere thing", a "simple material object" on one pole of the scale and a "socialization device" or a "cultural projection" on the other. Does it mean that not one but several baby carriages were present at the same time at the same place? Not only material but also a "cultural" and, probably, a "socializing" one? Dualism proposed by the very axiomatic assumptions of symbolic interactionism [6] leads to the strange multiplication of baby carriages.

\section{How Simple ARE 'SIMPlE OBJECTS'?}

The Fig. 1 below is a picture taken in 1981 in Bekovo village, not far from my home city of Penza. The toy car presented was constructed by the local technical genius for his two sons (7 and 10) from the details he stole at the local factory where he used to work in the 1970-s. The toy is equipped with the small-capacity motor that makes it an amusing vehicle (though quite impractical considering the thickness and the depth of the Bekovo's mud).

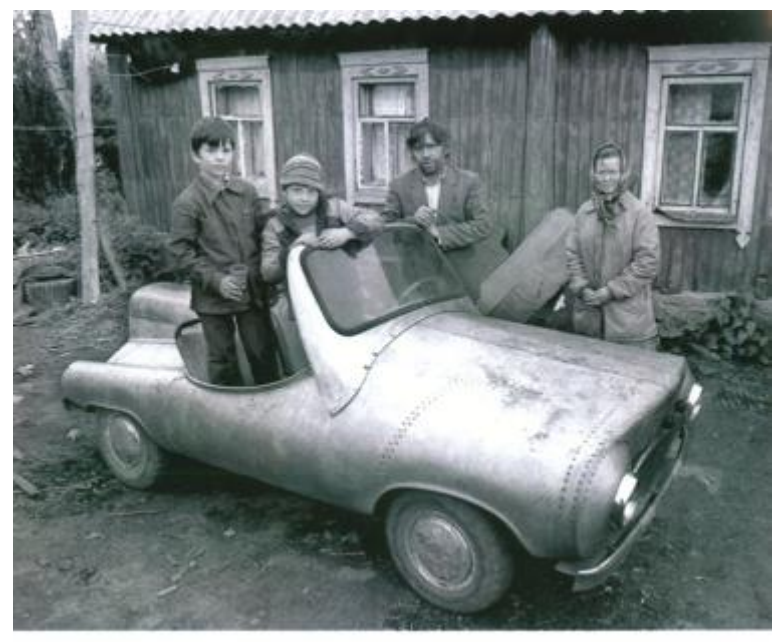

Fig. 1. The toy car.

Taking interactionist claim seriously we have to admit that there are two cars were created by the outstanding man. One - mere technical device - was constructed out of stolen details; while another - the real social toy - was constructed out of meanings, identities and probably the social reality 
itself. Sociologists have to make material car unproblematic in order to study social meanings invested in that toy. Consequently if this object is used by the sons in their play then it is a toy, and if it is used by their father to get to the local liquor store then it is a vehicle. Identity of an object thus is determined by the pragmatic context of its usage. ${ }^{1}$ Or, in another version of sociological determinism, by the narrative we apply to it. As Rom Harre summarizes: "There is nothing else to social life but symbolic exchanges and the joint construction and the management of meaning, including the meaning of bits of stuff. To become relevant to human life material beings must be interpreted for them to play a part in a human narrative" [14].

However these narratives are not just "...historically and culturally local"; they are inscribed in the toy car as possible scenarios of interaction with it. They do not exist out-there, in a transcendent kingdom of culture, values and meanings. Narratives are inscriptions. The toy car tells to its driver what to do: to turn the steering wheel, to press on the brake, to switch the clutch. Repertoire of actions that should be performed with this toy car is already inscribed in its material shape and technical construction. Doesn't look like the kids on the picture need a special handbook to imagine themselves driving it. Using Bruno Latour's term we can say that playing with a material toy is a work of delegation [15]. Some actions are delegated to the car and through the car re-delegated to the player.

Let's take the next step and compare this repertoire of inscriptions with another important characteristic of an object: its affordances [16]. The toy car affords both driving and playful driving. (As opposed to my favorite baby carriage which affords only the latter.) It also affords jumping on the sit, imitating a road accident, performing intentional and non-intentional stunts etc. Thereby if inscriptions tell us what we are supposed to do with a toy, affordances show what we can do with it.

Repertoire of affordances is never equal to the repertoire of inscriptions. And that rule is applicable to all material toys (but not to the computer ones). With a material toy you can always do more then you are supposed to. In this ratio of inscription to affordance we can find the major difference between the Soviet toy construction sets and the Lego ones. Soviet construction sets are philosophically open to the world if some parts of it didn't fit each other (and they never did) you were meant to use the father's toolkit - bolts, screwdriver and combination pliers - to make something out of it. The repertoire of inscriptions was refreshingly narrow. In the Soviet construction sets everything could be constructed out of everything and it was never clear what actually was supposed to be constructed. It's important here not to make an easy interpretative move and not to attribute this peculiar specificity of the Soviet construction set to the monstrous Soviet Culture. Even more important to keep microsociological purity and not to slip into the tempting psychological story (which involves such terms as "creativity" and "imagination training").

That "inscriptions / affordance" ratio is not constant. For

${ }^{1}$ For that purpose Harold Garfinkel used the concept of "oriented object" and even more enigmatic "as-of-which object". example, breaking the toy can make it even more attractive: it is the chance to re-write scenario, re-inscribe and re-code a plaything.

\section{THE TOY INCEPTION}

Can we say that inscriptions belong to the "meaningful" pole of the interactionists' scale while affordances are a part of its "material" side? Or, in terms of Harre, inscriptions belong to the symbolic orders while affordances characterize only simple "bits of stuff"? No. There is no dualism of inscription and affordance, no multiplication of the toy car. Quite the reverse, we can hardly distinguish inscriptions from affordances. The very distinction between them is a pure analytical construction. (E.g., the work of delegation is based on both characteristics.) There is only one car which is as much symbolic as it is material.

Erving Goffman suggested a tempting concept of keying, which prima facie helps us to distinguish symbolic and material dimensions of interaction. According to Goffman the play is always a "non-literal realm" [17]. This means that all material objects involved in a play are second-degree objects, just like stage props. Meaning of such second-degree object is predefined by the frame of interaction. Transposition of an object into a "second-degree" framework is a form of keying. Dual (symbolic / material) nature of a thing supposedly makes such keying possible. For example, a safety belt in a car. It is both a material thing that interacts with your material body (especially in the case of an accident) and at the same time it is the signal telling to a road police officer: "I'm a law-abiding citizen; you have no reason to stop me". (Gregory Bateson would probably call it a meta-communicative message.) Russian drivers announced a cold war to safety belts. They usually not fasten these restricting devices but just slip them on. In Goffmanian terms it is a keying. Safety belt is still a material thing but it doesn't interact with your body directly anymore. However it still works as a signal for a police officer. Safety belt became a second-degree object. And here comes the re-keying among people who spent plenty of time driving the new fashion has emerged: white shirts with a black strip across a chest imitating a safety belt. Now safety belt is transposed into a pure sign addressed to an anonymous police officer, a non-existing object.

In Goffman's theory relations between symbolic and material dimensions of a toy are always asymmetrical: the framework of a play presupposes that toys are standing for something. They are more signs then things. Even if we take such complicated toys as the Bekovo car. It is the "literal" car and "non-literal" second-degree car, the sign of itself. However this theoretical logic doesn't allow us to see two important feature of playful interaction.

Firstly, play is event-producing interaction. Kids don't play with meanings - they play with objects. By re-writing inscriptions, changing roles and re-coding toys they emotionally invest themselves in these objects. The process of emotional investment is something more fundamental than Goffman's "regimes of involvement".

Secondly, toys are performative. They do not just anchor 
the framework of a play they performatively transform it. That's why play is something always transcending its own limits.

Let's consider the dramaturgy of such performativity.

1) Imagine a boy constructing a castle using a Lego construction set;

2) After the castle is ready, he is taking a plasticine and creates little soldiers to inhabit the castle;

3) Then he takes a plastic toy arbalest and shoots the castle from a distance, trying to destroy all plasticine defenders.

What determines the shifts between episodes of the play? When he started to make the castle he didn't know yet what will be the next step. Combination of a Lego castle and plasticine defenders was also the emergent not planned assemblage. And of course, the cruel siege was spontaneous shift in the scenario. The plasticine soldiers are falling down, stimulating boy's imagination. They respond to his actions. Should we say that materiality of plasticine is something irrelevant for our analysis or at least less important than symbolic meanings attributed to the soldiers?

Another interesting feature: shifts between episodes are not re-keyings (there is no play within the play) they are re-shapings. New actors are introduced and the relation between inscriptions and affordances is changing. The same toy can be used as:

1) Setting - something that allows the play and defines its conditions of possibility, but not involved in interaction directly;

2) Equipment - an object of manipulation that is always materially involved in communication;

3) Actant - a toy-partner for communication.

Bruno Latour imports the concept of "actant" from A.-G. Greimas semiotics; it illustrates an object's ability to act independently within the social world.

\section{THE PARLIAMENT OF TOYS}

Here is the crucial difference between Goffmanian and Latourian approaches. For Goffman toys are anchors, holding and sustaining the framework of playful interaction. For Latour toys are inter-actants themselves. Goffman would probably stress their ability to be used as settings and equipment. Latour (famous also for his idea of the Parliament of Things) would suggest considering them as active and performative players.

I have at least one illustration to confirm the correctness of Latour's conceptualization.

Last winter right after the parliamentary elections the rising tide of civil protests spread across Russia. Authorities (especially regional ones) made their best to put obstacles in the way of protesters. Consequently a new form of protest has emerged in the Russian regions. So called "nano-meetings".

Toys equipped with opposition banners were placed in a city center of Barnaul. Being second-degree objects they are not suppose to be the subjects of the Russian law. However in the city of Barnaul police broke up the action as "an unsanctioned public event". A petition to hold another protest featuring 100 Kinder Surprise toys, 100 Lego people, 20 model soldiers, 15 soft toys and 10 toy cars has been rejected because the toys have been deemed not to be "citizens of Russia", reports The Guardian. "As you understand, toys, especially imported toys, are not only not citizens of Russia but they are not even people," Andrei Lyapunov, a spokesman for Barnaul, told local media. "It is possible that the people who have applied are inspired by their toys ... and consider them their friends but the law unfortunately has a different point of view," said Lyapunov. "Neither toys nor, for example, flags, plates or domestic appliances can take part in a meeting." [17].

According to Erving Goffman toys were used by political protesters in order to reframe the protest. So they were involved - strategically - as an equipment of interaction. However not only protesters themselves but also the city authorities see these toys rather as Latourian actants than Goffmanian equipment. Protesters support that conceptualization by organizing the play; authorities and police by breaking it up and declaring it "an unsanctioned public event". Even announcing toys to be "non-human by Russian law" authorities acted towards them as if they were potentially dangerous political activists. (By the way, all toys participated in the first rally were retained by the local police.)

Where is the border between equipment and actant? Should we assume that it is a pure analytic distinction like distinction between affordance and inscription? Or it is relational functional distinction that is determined by the frame of interaction? Of course, the same object can be involved both as equipment and as actant depending on the structure of interaction. However it is not a mere analytical construct. In the last analysis it emotional investment we discussed before is what can animate inanimate objects.

\section{REFERENCES}

[1] G. Brougere. (1998). The toy and the sociology of childhood. [Online] Available: http://www.musee-du-jouet.com/europe/sociology.doc

[2] K. D. Brown, "Modeling for war: toy soldiers in late Victorian and Edwardian Britain,” Journal of Social History, vol. 24, pp. 237-254, 1990.

[3] C. Buettner, "War toys or the organization of hostility," International Journal of Early Childhood, vol. 13, pp. 104-112, 1981.

[4] N. C. Paige and D. E. Levin, The War Play Dilemma: Balancing Needs and Values in the Early Childhood Classroom, New York: Teacher College Press, 1987.

[5] D. Ball, "Toward a sociology of toys: inanimate objects, socialization, and the demography of the doll world," The Sociological Quarterly, vol. 3, pp. 447-458, 1967.

[6] H. Blumer, Symbolic Interactionism; Perspective and Method, Englewood Cliffs, NJ: Prentice-Hall, 1969.

[7] A. L. Masters, "Some thoughts on teenage mutant ninja turtles: war toys and post-Reagan America," Journal of Psychohistory, vol. 17, pp. 319-326, 1990.

[8] B. S. Smith, "War toys and childhood aggression," Play and Culture, vol. 1, pp. 57-69, 1988.

[9] D. R. Cox, "Barbie and her playmates," Journal of Popular Culture, vol. 11 , pp. 303-307, 1977.

[10] M. F. Motz, "I want to be a Barbie girl when I grow Up: the cultural significance of the Barbie doll," The Popular Culture Reader, OH: Bowling Green University Popular Press, 1983, pp. 123-136.

[11] C. W. Pursell, "Toys, technology and sex roles in America, 1920-1940," Dynamos and Virgins Revisited, NJ: Scarecrow Press, 1979, pp. 252-267.

[12] D. Y. Wilkinson, "The Doll Exhibit: A Psycho-Cultural Analysis of Black Female Role Stereotypes," Journal of Popular Culture, vol. 21, pp. 19-29, 1987.

[13] S. N. Rowe, "Ritual, magic, and education toys: symbolic aspects of toy selection," Troubling Children: Studies of Children and Social Problems, New York: Aldine, 1994. 
[14] R. Harre, "Material objects in social worlds," Theory, Culture and Society, vol. 5/6, pp. 23-34, 2002.

[15] B. Latour, "On interobjectivity," Mind, Culture, and Activity: An International Journal, vol. 3, pp. 228-245, 1996.

[16] J. J. Gibson, "The theory of affordances," in Perceiving, Acting, and Knowing: Toward an Ecological Psychology, R. Shaw and J. Bransford Eds. Hillsdale, NJ: Lawrence Erlbaum, 1977.

[17] E. Goffman, Frame Analysis: An Essay on the Organization of Experience. Cambridge' Harvard University Press, 1974.

[18] Toys cannot hold protest because they are not citizens of Russia, The Guardian, Thu, 16 Feb. 2012.

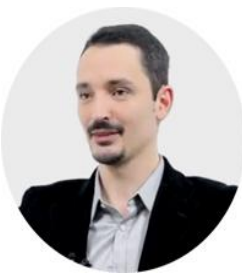

Victor Vakhshtayn is the head of Theoretical Sociology and Epistemology Department at Russian Presidential Academy of National Economy and Public Administration and professor in the Department of Social Sciences at the Russian-British university Moscow School of Social and Economic Sciences since 2008 (Moscow, Russia).
In 2007 completed his Ph.D. and defended the thesis on everyday interactions investigations. He participated in the projects of the World Bank, OECD, OSCE, National Democratic Institute of USA, several European universities. Worked in Bosnia, Herzegovina, Albania, Hungary, Croatia, USA, Israel. He has published more than 30 articles in academic and professional journals on Russian, English and German languages.

Victor Vakhshtayn is an author of the following books: "Theory of frames and sociology of everyday life" (EU, St. Petersburg, 2011), "Reality of Education and Research Practices (HSE, 2010, co-authored). His research interests lie in the area of sociology of materiality, epistemology of social sciences, frame-analysis, Sociology of everyday life. 